\title{
The role of the transnational ultra-processed food industry in the pandemic of obesity and its associated diseases: problems and solutions
}

\section{Carlos A. Monteiro}

Department of Nutrition, School of Public Health, and Center for Epidemiological Studies in Health and Nutrition, University of São Paulo

\section{Geoffrey Cannon}

Center for Epidemiological Studies in Health and Nutrition, University of São Paulo

Adapted from a background paper prepared for the session 'The Commercial Determinants of Non-Communicable Diseases' at the Prince Mahidol Award Conference 2019 'The Political Economy of NCDs: A Whole of Society Approach', Bangkok, Thailand, 29 January - 3 February 2019

\section{Abstract}

Policies to control and prevent the pandemic of obesity and related conditions and diseases have failed. This is because the efficient causes of the pandemic have not yet been agreed. We state here that its outstanding immediate cause is the increased and rapidly increasing consumption of ultra-processed foods, which displace unprocessed or minimally processed foods and freshly prepared dishes and meals, most conspicuously now in middle- and lower-income countries.

The underlying cause of this is the phenomenal rise since the 1980s of the transnational corporations whose huge profits depend on the use of cheap ingredients and arrays of additives made into ultra-processed food. The scale and power of the transnationals, which tend towards oligopoly, and their penetration of middle and lower-income countries, have been accelerated by global political and economic agreements that have deregulated trade and allowed capital flow that opens countries to penetration by foreign businesses.

Food is essential for life and health, but there is no need to consume ultra-processed foods. In this sense, they are similar to tobacco products. The same statutory policies and programmes that are applied to smoking should be adapted to limit and reduce consumption of ultra-processed foods. Revenue from taxation should be used to protect local food producers and retailers, to promote healthy and sustainable diets, and to 
ensure food security for vulnerable populations. Overall, a Framework Convention on Food Systems, promulgated by the relevant United Nations agencies as agreed by UN member states, supported by professional and civil society organisations and social movements, is needed. This will be designed to create healthy food systems and supplies and thus healthy diets that also are beneficial socially, culturally, economically and environmentally.

Key words: Obesity; Food processing; Ultra-processed food; Food processing; Transnational corporations; Deregulation; Statutory policies.

Epidemics resemble great warning signs on which the true statesman is able to read that the evolution of his nation has been disturbed to a point which even a careless policy is no longer allowed to overlook.

(Rudolf Virchow) (1)

\section{The stakes}

A number of phenomenal global catastrophes confront humanity, including 'superbugs' resistant to antimicrobial drugs; cigarettes and other use of tobacco; alcohol abuse; climate disruption; gross inequities; and the pandemic of obesity and diseases of which obesity is a leading cause, notably diabetes, cardiovascular diseases and a number of common cancers. These dreadful calamities are similar in various ways. None are natural. All are disastrous socially and economically as well as personally.

There is however one difference. The causes of the first five phenomena mentioned here are known beyond reasonable doubt, and public policies and actions that would reduce the devastation they cause are generally agreed beyond reasonable argument. But this is not the case with obesity and related diseases. Their causes are still debated, and their remedies disputed.

The purpose of this commentary is to identify the basic causes of the pandemic (world epidemic) of obesity, and to propose appropriate solutions. General agreement involving governments, professional and public interest organisations and citizen movements, is needed to ensure coherent and concerted policies and actions.

What is meant by 'cause' here is not the immediate cause, but what Aristotle termed the efficient cause (2), or agent, also sometimes termed the vector. The main basic agents or vectors of what is now pandemic obesity are the transnational corporations whose profits depend on the manufacture, promotion and sale of ultra-processed food and drink products. This conclusion is supported directly or indirectly by the findings of over 200 papers published since 2010 in peer-reviewed journals as listed in the Medline database, from researchers working in a large number of independent academic institutions in various regions of the world. Some of these findings are summarised and referenced below. 


\section{The problem}

Food processing is not the issue. Food processing as such is not a health problem, and criticisms of 'processed food' are therefore confusing and misleading. Most food is industrially processed in some way, and various forms of processing are useful or beneficial, as for example drying and wrapping, non-alcoholic fermentation, chilling and freezing, pasteurizing and vacuum-packing.

The problem is ultra-processed foods, as defined by the NOVA food classification system $(3,4)$. These products are characteristically ready-to-consume industrial formulations of homogenised cheap ingredients obtained from high-yield crops, notably sugars and syrups, refined starches, oils and fats, protein isolates, and also sometimes from remnants of intensively reared animals. Such formulations are made to look, smell, and taste good or often irresistible, by use of sophisticated combinations of flavours, colours, emulsifiers, sweeteners, thickeners and other additives that have a cosmetic function.

Processes and ingredients used for the manufacture of ultra-processed foods are designed to create highly profitable branded products made from low-cost ingredients, with long shelf-lives, which are liable to displace the production and consumption of unprocessed or minimally processed foods, processed foods, and freshly prepared dishes and meals - or simply 'real food' for short. Their convenience, being imperishable and ready-to-consume, their hyper-palatability, branding and ownership by huge transnational corporations, their universal availability, and their aggressive marketing, give ultra-processed foods enormous market advantages over 'real food' $(3,4)$.

Ultra-processed foods as a group have higher energy density, more sugar and unhealthy fats, and less dietary fibre, protein, vitamins and minerals, than non-ultra-processed foods, and their consumption is systematically associated with the deterioration of the overall nutritional quality of diets. This has been shown in studies, mostly using national dietary surveys, carried out in Brazil, Chile, Colombia, Mexico, the US, Canada, the UK, France, Belgium, Australia, New Zealand and Japan (5-24).

Experimental studies show that ultra-processed foods have low satiety potential, induce high glycaemic responses (25), and create a gut environment favouring microbes that promote inflammatory diseases (26). Cross-sectional and longitudinal studies show dose-response association between the dietary contribution of ultra-processed foods and obesity (27-30), and also hypertension (31), cardiovascular diseases (32), dyslipidaemia (33), metabolic syndrome (34), gastrointestinal disorders (35), total and breast cancer (36), depression (37), and all-cause mortality $(38,39)$. An in-patient, two-week, crossover randomized controlled trial conducted by the US National Institutes of Health compared diets with an average of 83\% of energy from ultra-processed foods with diets containing no ultra-processed foods (40). The main findings of the trial showed that "when consuming ultra-processed food diets people ate on average 508 more calories per 
day $\ldots$ and that, not surprisingly given this finding, people gained weight on the ultraprocessed diet (1.7lbs in just 2 weeks) and lost weight on the flip side (2.4lbs in just 2 weeks)" (41).

The nature of the processes and ingredients used in their manufacture, and their displacement of the production and consumption of 'real food', make ultra-processed foods intrinsically harmful to human health. This displacement is also a cause of social, cultural, economic, political and environmental disruption and crises, described elsewhere (3).

National dietary intake surveys show that ultra-processed foods may make up close to or even more than half of the total dietary energy consumed in some high-income countries such as the USA, Canada, the UK and Australia, $(17-18,21,42)$ and now between one fifth and one third of total dietary energy in middle-income countries $(8,9,43)$. Statistics on global sales confirm the higher consumption of ultra-processed foods in high-income countries and show rapid and even exponential growth in middleincome countries. For example, between 1998 and 2012 sales of sugary and salty snacks and soft drinks increased by 50\% in upper middle-income countries and more than 100 per cent in lower middle-income countries (44).

Population body weight has risen in parallel with the rise in the production and consumption of ultra-processed foods. In fifteen Latin American countries, increases in sales of ultra-processed products such as carbonated soft drinks, sugary or salty packaged snacks, biscuits, sweetened breakfast cereals, confectionery, ice cream and ready-to-heat pre-prepared meals between 2000 and 2009 were strongly associated with increases in population mean body mass indices (45). A similar study carried out between 2002 and 2014 using data from 80 countries in eight world regions shows similar results (46).

\section{The problem behind the problem}

Since the 1980s, the size and the reach of the transnational corporations whose profits depend on the manufacture and sale of ultra-processed food products have spectacularly increased. This is the problem behind the problem. These corporations, like the tobacco, alcohol and drug transnationals, tend towards oligopoly. While competitive in markets for specific product ranges, they all have the same overall policy, which is to magnify their political and economic power over the rest of the food industry as a whole, numerically far greater, including smaller manufacturers, producers, retailers and caterers.

Together, the revenues of ten giant transnational ultra-processed food corporations in 2017-2018 (Nestlé, PepsiCo, Unilever, Mondelēz/Kraft, Coca-Cola, Mars, Danone, Associated British Foods, General Mills, Kellogg's) amounted to more than a billion dollars a day (47). In that time period, the annual sales of Nestlé, with its 2,000 brands, 
including baby formula and baby foods, packaged snacks, chocolate confectionery, breakfast 'cereals', ice cream, pre-prepared dishes, and instant soups and sauces, amounted to \$US 91.2 billion, and its profits to \$US 7.3 billion (48). Nestlé's sales are roughly the same as the gross national product (GDP) of Sri Lanka and of Kenya (49). The annual sales of Pepsi-Co brands, whose brands are mostly ultra-processed packaged snacks and soft drinks, amounted to \$US 63.5 billion, and its profits to \$US 10.8 billion. (50). In each of Brazil, India, Mexico and Russia, one of the two market leaders in total packaged foods is transnational, and Nestlé is always one of the top three (51).

Since the 1980s, 'neo-liberal' economic policies and trade agreements formulated and enacted by global organisations supported by the most powerful governments have favoured transnational corporations. These policies and agreements have deregulated industry, promoted capital flow, opened countries to foreign investment, enabled transnationals to take over domestic companies, and constrained national governments from introducing statutory policies to limit consumption of ultra-processed foods (52). Meanwhile, increases in disposable income have made ultra-processed foods affordable for more people.

The transnational food corporations mount colossal mass-marketing campaigns, co-opt policy makers and health professionals, and lobby politicians and public officials to oppose public regulation. They fund and promote biased research, media stories and 'infomercials', and press citizens to oppose public health regulation of their industry (52). They found, fund and control organisations, some seemingly independent, that represent their joint interests, notably based in Washington DC, Geneva or Brussels (5355). One declares 'Our member companies represent the global leaders of the food and non-alcoholic beverage industry. We employ more than 3 million people worldwide and had combined annual revenues in 2016 of over USD 410 billion’ (50).

The first and foremost loyalty of corporations is to their financiers and their shareholders. The profitability of ultra-processed food corporations depends on products being formulated from the cheapest ingredients. They successfully influence policymakers to subsidize crops they process, such as maize (corn) and soy, rather than healthier foods. Therefore, their interests are unavoidably in conflict with those of public health. They compete for market share, but they all have an overall strategy in common. To adapt the slogan sung in an old Coca-Cola advertisement, they want to "teach the world to snack" and thus displace freshly prepared dishes and meals, and build loyalty to their brands - in the case of Nestlé, from cradle to grave.

\section{The mistaken 'solution'}

One standard response of transnational corporations to evidence that their products are causing the obesity pandemic is product reformulation. This strategy is now even supported by some policy-makers outside industry. This is not a solution. Changing one problematic ingredient for another, such as less fat but more sugar, or sugar replaced by artificial sweeteners, does not make ultra-processed foods healthy. Reformulated 'premium’ ultra-processed lines ‘enriched' with micronutrients and fibre sold with 
health claims at higher prices could prove to be comparably more profitable, but would remain unhealthy products. A detailed analysis of the limits of product reformulation of ultra-processed foods has been published elsewhere (56).

In 2014, a Lancet Action Group on Non-Communicable Diseases (52) examined reformulation, stating: 'The case for reformulation is most apparent in high-income countries where markets might be saturated with ultra-processed products... [Here]... consumers might prefer the new product without consuming more ultra-processed products... Nonetheless, in such countries, the main emphasis on and support of national governments and the public health community should be promotion of healthy meals, dishes, and foods'.

Also: 'In low-income countries, benefits are less obvious, and the dangers are very apparent. In such countries, consumption of ultra-processed products is low. These countries are therefore the prime targets of transnational corporations. If they reformulate, advertise, and promote some of their less unhealthy products as healthy e.g., sodium-reduced (but still high energy-dense) packaged snacks or artificially sweetened (but still nutrient-devoid) soft drinks - the overall consumption of ultraprocessed products is likely to increase, which would undermine long-established dietary patterns based on fresh or minimally processed foods. In low-income countries, the reformulation of ultra-processed food and drink products is similar to the tactics of the tobacco industry in the introduction of filtered cigarettes and low-tar cigarettes'.

The conclusion of The Lancet Action Group was: 'The reformulation approach is a damage-limitation exercise, to avoid evidence-based approaches such as the restriction of availability and of advertising, and pricing policies designed to promote healthy food'.

\section{The rational solution}

What to do? It is often said that food is not like tobacco or alcohol, in that food is necessary for life. This is true. But there is no need to consume ultra-processed products, which in this respect are therefore similar to tobacco and alcohol. So the solution becomes obvious. International agencies and governments, encouraged by public interest civil society organisations and social movements, and supported by public health authorities, should design and implement statutory including fiscal public policies and actions, designed to control and reduce the manufacture, sale, promotion, availability and consumption of ultra-processed products, similar to those used to control and reduce use of tobacco and consumption of alcoholic drinks. The collaboration of government departments and international and national organisations responsible for social, cultural, agricultural, financial and environmental regulations and other public action, as well as those of health, will be essential. Actions should include regularly updated estimates of the financial and other costs of the personal, social, cultural, and environmental impacts of ultra-processed foods, and of the corresponding 
financial and other benefits of methods that encourage healthy food and freshly prepared meals.

Rational policies and actions agreed globally and applied nationally will promote sustainable and equitable agriculture, manufacture, distribution, retailing and catering. All subsidies and other incentives to grow crops solely or mostly used as ingredients in ultra-processed food, or as feed for animals mostly destined to be used in ultraprocessed food, should be removed, and destruction of forests and other environmentally valuable land to grow such crops or to rear animals should be prohibited.

Taxes should be levied at two stages. The first tax should be on ingredients exclusively used by ultra-processed food manufacturers, in particular cosmetic additives. The second tax should be on the product as sold to consumers. The levels of taxation should be calculated to generate revenue equivalent to a substantial percentage of the profits currently made by the corporations.

The tax revenues gained should be sequestered and be sufficient to fund programmes designed to support production and consumption of healthy food, to improve public health, and to monitor progress. Much of the revenues should be used to support local co-operative and family farmers and small traders, to make unprocessed and minimally processed food more available and affordable, to ensure healthy meals in schools, hospitals and prisons, and to subsidize or otherwise lower or stabilise the retail prices of unprocessed and minimally processed foods so as to be affordable by vulnerable communities and families.

All advertising and promotion of ultra-processed products should be prohibited, and their labels should include prominent warnings. Special consideration needs to be given to institutional food. No ultra-processed food should be available in any form at workplaces, schools, hospitals and prisons, and no outlets selling ultra-processed food should be allowed within convenient walking distance of schools. Household economy and food preparation and cooking should be taught in all schools.

In summary, with ultra-processed food products, lessons should be learned from what has worked best to ensure tobacco control and reduction of smoking. Concerted action by international agencies and national governments, backed by professional and public interest organisations and citizen action groups, is needed. We support the proposal for a Framework Convention on Food Systems, as recommended by the 2019 Lancet Commission in what it identifies as the global syndemic of obesity, undernutrition, and climate change (57)

It is not just Big Tobacco anymore. Public health must also contend with Big Food, Big Soda, and Big Alcohol. All of these industries fear regulation, and protect themselves by using the same tactics. ... These... include front groups, lobbies, promises of self-regulation, lawsuits, and industry-funded research that confuses the evidence and keeps the public in doubt... This is formidable opposition. Market power readily translates into political power. Few 
governments prioritize health over big business...Not one single country has managed to turn around its obesity epidemic in all age groups. This is not a failure of individual will-power. This is a failure of political will to take on big business.

(Margaret Chan, former Director General of WHO) (58).

\section{References}

1 Virchow R (1985). The epidemics of 1848. In Rather LF, editor. Rudolf Virchow: Collected Essays on Public Health and Epidemiology. 1985: Canton, MA: Watson Publishing International

2 Preus A (2015). 'Material cause'. Historical Dictionary of Ancient Greek Philosophy 2nd edition. Lanham, MD: Rowman and Littlefield. ISBN 9780810854871

3 Monteiro CA, Cannon G, Moubarac J-C et al. (2018). The UN Decade of Nutrition, the NOVA food classification and the trouble with ultra-processing. Public Health Nutr 21, 5-17.

4 Monteiro CA, Cannon G, Levy RB et al. (2019). Ultra-processed foods: what they are and how to identify them. Public Health Nutr. On-line February 2019

5 Monteiro CA, Levy RB, Claro RM et al. (2011). Increasing consumption of ultraprocessed foods and likely impact on human health: evidence from Brazil. Public Health Nutr 14, 5-13.

6 Costa Louzada ML, Martins AP, Canella DS et al. (2015). Ultra-processed foods and the nutritional dietary profile in Brazil. Rev Saude Publica 45, 38.

7 Louzada MLC, Martins APB, Canella DS et al. (2015). Impact of ultra-processed foods on micronutrient content in the Brazilian diet. Rev Saude Publica 49, 45.

8 Louzada MLDC, Ricardo CZ, Steele EM et al. (2018). The share of ultraprocessed foods determines the overall nutritional quality of diets in Brazil. Public Health Nutr 21, 94-102.

9 Cediel G, Reyes M, da Costa Louzada ML et al. (2018). Ultra-processed foods and added sugars in the Chilean diet (2010). Public Health Nutr 21, 125-133.

10 Parra DC, da Costa-Louzada ML, Moubarac JC et al. (2019). The association between ultra-processed food consumption and the nutrient profile of the Colombian diet in 2005. Salud Publica Mex. 2019;61.

11 Marrón-Ponce JA, Flores M, Cediel G et al. (2018). Consumption of ultraprocessed foods and the intake of non-communicable diseases related nutrients in Mexico. Paper in review.

12 Poti JM, Mendez MA, Ng SW et al. (2015). Is the degree of food processing and convenience linked with the nutritional quality of foods purchased by US households? Am J Clin Nutr 101, 1251-62.

13 Martinez Steele E, Baraldi LG, Louzada ML et al. (2016). Ultra-processed foods and added sugars in the US diet: evidence from a nationally representative crosssectional study. BMJ Open 14;15(1):6. 
14 Steele EM, Popkin B, Swinburn B et al. (2017). The share of ultra-processed foods and the overall nutritional quality of diets in the US: evidence from a nationally representative cross-sectional study. Popul Health Metr 15, 6.

15 Martinez Steele E, Raubenheimer D, Simpson SJ et al. (2018). Ultra-processed foods, protein leverage and energy intake in the USA. Public Health Nutr 21, 114124.

16 Moubarac JC, Martins AP, Claro RM et al. (2013). Consumption of ultraprocessed foods and likely impact on human health. Evidence from Canada. Public Health Nutr. 16, 2240-8

17 Moubarac J-C, Batal M, Louzada ML et al. (2017). Consumption of ultraprocessed foods predicts diet quality in Canada. Appetite 108, 512-520.

18 Rauber F, Louzada MLC, Steele EM et al. (2018). Ultra-processed food consumption and chronic non-communicable diseases-related dietary nutrient profile in the UK (2008-2014). Nutrients 9;10(5).

19 Julia C, Martinez L, Allès B et al. (2018). Contribution of ultra-processed foods in the diet of adults from the French NutriNet-Santé study. Public Health Nutr 21, 27-37.

20 Vandevijvere S, Ridder KD, Fiolet T et al. (2018). Consumption of ultraprocessed food products and diet quality among children, adolescents and adults in Belgium. Eur J Nutr 2018. On-line December 2018.

21 Machado PP, Steele E, Levy RB et al. (2018). Ultra-processed foods and recommended intake levels of nutrients linked to non-communicable diseases in Australia: evidence from a nationally representative cross-sectional study. Paper in review.

22 Luiten CM, Steenhuis IH, Eyles H et al. (2016). Ultra-processed foods have the worst nutrient profile, yet they are the most available packaged products in a sample of New Zealand supermarkets. Public Health Nutr 19, 530-8.

23 Koiwai K, Takemi Y, Hayashi F et al. (2018). Consumption of ultra-processed foods decreases the quality of the overall diet of middle-aged Japanese adults. Public Health Nutr (Accepted).

24 Cornwell B, Villamor E, Mora-Plazas et al. (2018). Processed and ultra-processed foods are associated with lower-quality nutrient profiles in children from Colombia. Public Health Nutr. 21:142-147.

25 Fardet A (2016). Minimally processed foods are more satiating and less hyperglycemic than ultra-processed foods: a preliminary study with 98 ready-toeat foods. Food Funct 7, 2338-2346.

26 Zinöcker MK, Lindseth IA (2018). The Western diet-microbiome-host interaction and its role in metabolic disease. Nutrients 17;10(3). pii: E365.

27 Louzada MLC, Baraldi LC, Steele EM et al. (2015). Consumption of ultraprocessed foods and obesity in Brazilian adolescents and adults. Preventive Medicine 81, 8-15.

28 Mendonça R, Pimenta A, Gea A et al. (2016). Ultra-processed foods consumption and risk of overweight/obesity: the SUN cohort study. Am J Clin Nutr 104, 14331440 . 
29 Juul F, Steele EM, Parekh N et al. (2018). Ultra-processed food consumption and excess weight among US adults. Br J Nutr 120, 90-100.

30 Nardocci M, Leclerc B-S, Louzada MLC et al. (2018). Consumption of ultraprocessed foods and obesity in Canada. Can J Public Health 110(1):4-14.

31 Mendonça R, Lopes A, Pimenta AM et al. (2017). Ultraprocessed food consumption and the incidence of hypertension in a Mediterranean cohort: the Seguimiento Universidad de Navarra Project. Am J Hypertens 30, 358-366.

32 Srour B, Fezeu L, Kesse-Guyot E et al. (2019). Ultra-processed food intake and cardiovascular disease risk in the NutriNet-Santé prospective cohort. BMJ. (Accepted).

33 Rauber F, Campagnolo PDB, Hoffman DJ et al. (2015). Consumption of ultraprocessed food products and its effects on children's lipid profiles: a longitudinal study. Nutr Metab Cardiovasc Dis 25, 116-122.

34 Lavigne-Robichaud M, Moubarac J-C, Lantagne-Lopez S et al. (2018). Diet quality indices in relation to metabolic syndrome in an Indigenous Cree (Eeyouch) population in northern Québec, Canada. Public Health Nutr 21, 172180.

35 Schnabel L, Buscail C, Sabate J-M et al. (2018). Association between ultraprocessed food consumption and functional gastrointestinal disorders: results from the French NutriNet-Santé Cohort. Am J Gastroenterol. Published online: 15 Jun 2018.

36 Fiolet T, Srour B, Sellem L et al. (2018). Consumption of ultra-processed foods and cancer risk: results from NutriNet-Santé prospective cohort. BMJ 360:k322.

37 Gómez-Donoso C, Sánchez-Villegas A, Martínez-González MA et al. (2018). Depression Ultra-processed food consumption and the incidence of depression in a Mediterranean cohort: The SUN Project. Paper in review.

38 Schnabel L, Kesse-Guyot E, Allès B et al. (2019). Association between ultraprocessed food consumption and risk of mortality among middle-aged adults in France. JAMA Intern Med. Published online February 11, 2019.

39 Kim H, Hu E, Rebholz C (2019). Ultra-processed food intake and mortality in the USA: Results from the Third National Health and Nutrition Examination Survey (NHANES III, 1988-1994). Public Health Nutrition, 1-9.

40 Hall K, Ayuketah A, Bernstein S et al. (2018). Ultra-processed diets cause excess calorie intake and weight gain: A one-month inpatient randomized controlled trial of ad libitum food intake. 11 February. Pre-print doi: 10.31232/osf.io/w3zh2

41 Freedhoff Y (2019). Groundbreaking new study on ultra-processed foods provides possible causal smoking gun for our global obesity struggles. Weighty Matters. 12 February 2019

42 Baraldi LG, Martinez Steele EM, Canella DS et al. (2018). Consumption of ultraprocessed foods and associated sociodemographic factors in the USA between 2007 and 2012: evidence from a nationally representative cross-sectional. BMJ Open 9:8(3): 020574.

43 Marrón-Ponce JA, Sánchez-Pimienta TG, Louzada M et al. (2018). Energy contribution of NOVA food groups and sociodemographic determinants of ultra- 
processed food consumption in the Mexican population. Public Health Nutr 21(1):87-93.

44 Monteiro CA, Moubarac J-C, Cannon G et al. (2013). Ultra-processed products are becoming dominant in the global food system. Obesity Reviews 14, 21-28.

45 Pan American Health Organization of the World Health Organization (2015). Ultra-Processed Food and Drink Products in Latin America: Trends, Impact on Obesity, Policy Implications. Washington, DC: PAHO; available at http://www.paho.org/hq/index.php?option=com_content\&view=article\&id=11153 \%3Aultra-processed-food-anddrinkproducts\&catid=4999\%3Adocuments\&lang=em

46 Vandevijvere S, Lindsay J, Monteiro CA et al. (2019). Global trends in ultraprocessed food and drink product sales and their association with adult body mass index trajectories, 2012-2014. Obesity Reviews (Accepted).

47 Oxfam (2013). Behind the Brands. Methodology summary. Available at: https://www.behindthebrands.org/images/media/Downloadfiles/BehindTheBrandsMethodologySummary-26Feb13-EN.pdf

48 Forbes (2018). Global 2000. The World's Largest Public Companies. Jersey City, NJ: Forbes, June. https://www.forbes.com/global2000/\#2f488dea335d

49 International Monetary Fund (2018). World Economic Outlook. Washington, DC, April. https://www.imf.org/en/Publications/WEO/Issues/2018/07/02/worldeconomic-outlook-update-april-2018

50 Pepsi-Co (2017). Annual Report. Performance with purpose. Available at: https://www.pepsico.com/docs/album/investor/pepsico-inc-2017-annualreport.pdf

51 Stuckler D, McKee M, Ebrahim S, Basu S (2012). Manufacturing epidemics: the role of global producers in increased consumption of unhealthy commodities including processed foods, alcohol, and tobacco. PLoS Med 9(6): e1001235.

52 Moodie R, Stuckler D, Monteiro CA et al. (2013). Profits and pandemics: prevention of harmful effects of tobacco, alcohol, and ultra-processed food and drink industries. Non-communicable Diseases Series 4. Lancet 381, 670-679.

53 International Food and Beverage Alliance. https://ifballiance.org/

54 International Food Information Council. https://foodinsight.org/

55 International Life Sciences Institute. http://ilsi.org/

56 Scrinis G, Monteiro CA (2018). Ultra-processed foods and the limits of product reformulation. Public Health Nutr 21(1), 247-252.

57 Swinburn B, Kraak V, Allender S et al. (2019). The Global Syndemic of Obesity, Undernutrition, and Climate Change: The Lancet Commission report. The Lancet 393: 791-846

58 Chan M, Director-General of the World Health Organization (2013). Opening address at the 8th Global Conference on Health Promotion. Helsinki, Finland, June. http://www.who.int/dg/speeches/2013/health_promotion_20130610/en/ 